\title{
Encounters between multicultural family members and the nurses in the context of intensive care
}

\author{
Sevald Høye ${ }^{* 1}$, Kari Kvigne ${ }^{1,2}$, Sture Åström ${ }^{3,4}$, Elisabeth Severinsson ${ }^{5}$, Inger Öster ${ }^{6}$ \\ ${ }^{1}$ Department of Nursing, Faculty of Public Health, Hedmark University College, Norway \\ ${ }^{2}$ Department of Nursing, Nesna University College, Norway \\ ${ }^{3}$ Department of Nursing, Faculty of Medicine, Umeå University, Sweden \\ ${ }^{4}$ Department of Nursing, Health and Culture, University West, Sweden \\ ${ }^{5}$ Department of Nursing Science, Centre for Women's, Family \& Child Health, Faculty of Health Sciences, Buskerud \& \\ Vestfold University College, Norway \\ ${ }^{6}$ Department of Nursing and Department of Community Medicine and Rehabilitation, Faculty of Medicine, Umeå University, \\ Sweden
}

Received: September 30, 2014

Accepted: November 18, 2014 Online Published: December 2, 2014

DOI: $10.5430 /$ cns.v3n1p89 URL: http://dx.doi.org/10.5430/cns.v3n1p89

\begin{abstract}
The increase in people on the move creates populations that are culturally diverse. People meet various challenges regarding the migration process, social life, jobs and health issues. When a person suffers from acute and critical illness, he/she may be in need of intensive care. The aim of this study was to explore the comprehension of culture, caring and gender among first and second generation immigrant women as relatives on their encounters with intensive care nurses in Norwegian hospitals. A design based upon discursive psychology to explore subject positions, interpretative repertoires and ideological dilemmas focused immigrant female relatives' experiences with a cultural and gender perspective. Immigrants who were relatives to critically ill people were interviewed. The results of the discourse analysis revealed the following themes: being the caring person as woman, being intertwined between the Western hospital culture and the original family culture and belonging to a minority in a Western majority culture. Conclusion: The women in the families with a critically ill family member mainly act as the caring person. There are dilemmas in how much every family transfer the responsibility for their loved one to the nurses. Anxious attitudes regarding caring activities are rarely linked to their cultural background.
\end{abstract}

Key Words: Immigrant, Women, Family member, Discourse analysis, Intensive care

\section{Introduction}

The increase in global mobility creates populations that are culturally diverse in almost all countries. The understanding of the relationship between migration and health is limited. ${ }^{[1]}$

Culture involves diversity concerning understanding of illness, disease, gender and family position. An understand- ing of culture is associated with common language, knowledge and values as well as mutual experiences transferred from earlier generations. ${ }^{[2]}$ Multiculturalism promotes diversity and recommends that all cultural groups should be treated with respect and equality. ${ }^{[3]}$ When a person with an immigrant background suffers an illness and encounters the Norwegian health system, the previous factors may be intertwined and create challenges for all family mem-

\footnotetext{
*Correspondence: Sevald Høye; Email: sevald.hoye@hihm.no; Address: Department of Nursing, Faculty of Public Health, Hedmark University College, P.O.Box 400, N-2418 Elverum, Norway.
} 
bers. $^{[4]}$ Biomedical medicine including pathological approaches dominates the understanding of disease in the Western world. Holistic medicine, including beliefs and balance between people and nature and between people and the supernatural world ${ }^{[5]}$ represent the dominant understanding of illness in Eastern societies. ${ }^{[6]}$

Immigrants to Norway are defined into two groups: Immigrants who were born abroad and moved to Norway by two foreign-born parents, and Norwegian-born children with two immigrant parents (descendants). Immigrants who were born abroad and moved to Norway are so-called first generation immigrants, while Norwegian-born children with two immigrant parents are called second generation immigrants. The immigrants in Norway and their Norwegian-born children constitute more than 12 percent of the whole population, or more than 710,000 persons. ${ }^{[7]}$ Norwegian statistics refer to second generation children as "immigrants" when in fact they are Norwegian nationals. Second generation immigrants are influenced by traditional Western perspectives like equal status and equal opportunities.

Gender is traditionally considered as a deep and stable structure. ${ }^{[8]}$ Gender in Western societies has been constructed through psychological, cultural and social means, unlike sex, which has been described by biology in terms of anatomy, hormones and physiology. ${ }^{[9]}$ Whether, for instance, gender is considered as a natural phenomenon or a constructed phenomenon depends upon who consider it to be natural. Gender and stereotypical roles are negotiated in everyday situations in the constantly changing society. Traditionally in most cultures women have a subordinate position in relation to men. ${ }^{[10]}$ According to Rosaldo ${ }^{[11]}$ and Lewellen, ${ }^{[12]}$ men are mostly engaged in activities in the public sphere or outside the home and independent of their family. On the contrary, women perform tasks at home for their own family, which may involve gender-specific work.

When a person suffers from acute and critical illness, he/she may be in need of intensive care and medical treatment in the intensive care units in hospitals. Care, the fundament for professional nursing, includes emotional involvement and empathy for the patient where nurses act in an unselfish way. ${ }^{[13]}$ In addition, the roles of the nurses and physicians will influence the intensive care culture in the way they communicate with the patients and their families, how they communicate with each other and how they interact with and to some extent lead cooperative health professionals. ${ }^{[14]}$

Nurses' experiences of caring for culturally diverse patients and their families is reported as complex due to the interrelatedness of multiple personal and contextual factors like the setting of health care, the support of colleagues, the institutional climate, the foundation of education, and the presence of different values. ${ }^{[15]}$

Nailon ${ }^{[16]}$ points out central factors to promote communication more effectively when linguistic differences occur with multi-linguistic families, such as nurses' skills working with interpreters, interpreter availability, and accuracy. Some nurses use the perspective of the individual patient and family, while others have stereotypical views of the patient's cultural group. ${ }^{[17]}$ In the comprehension of nurses encountering immigrants with different cultural and religious background, the nurses are often linked to nursing as a female activity, where the male patient or family members often fulfill these stereotypes. ${ }^{[18]}$ More than 90 percent of Norwegian nurses are female. ${ }^{[19]}$ When multicultural families encounter the Norwegian health system they mostly encounter female nurses, which represent the Western dominant construction of femininity. In Scandinavian countries the intensive care units and their milieu are mainly staffed by intensive care nurses. For that reason the families are primarily entrusted to female carers.

Previous investigations of encounters between family members with an immigrant history and nurses reveal various conflicts. In a study among intensive care nurses in Norway three different conflicts were unveiled: culturally based need to actively participate in the care versus nurses' professional perception of themselves as total care providers, nurses' professional obligation to provide comprehensible information versus culturally based communication difficulties and responses to illness and families' need for cultural norms and self-determination versus nurses' professional responsibility for the clinical environment. ${ }^{[4]}$ The term family refers to people who are bound together by emotional relations between members linked by socialization who define themselves as family. ${ }^{[20]}$ Families with an immigrant history are considered as families with a minority and different cultural background than Norwegian.

The aim of this study was to explore the comprehension of culture, caring and gender among first and second generation immigrant women as relatives on their encounters with intensive care nurses in Norwegian hospitals. The research question was: What subject positions, interpretative repertoires and ideological dilemmas are negotiated in stories of immigrant women in critical care nursing?

\section{Methods}

\subsection{Design}

Discourse analysis is described as a research method that "examines human speech and writing, actions and products (texts) to identify and analyse these ways of understanding". [21] Moreover, it is necessary to emphasize that there are "no formal procedures to do discourse analysis". [22] Instead, discourse analysis could be seen as an approach of a phenomenon in which to reveal contrasts, dichotomies and underlying opinions in human relations.

The design of the present study is based upon discourse analysis, while discursive psychology, a branch of discourse 
analysis, is used to focus on retrospective experiences of immigrant female relatives' encounters with nurses in intensive care units. To some extent, qualitative analysis will scrutinize the bases on which diverse interpretations of clinical phenomena are developed. ${ }^{[23]}$

The two concepts discourse and interpretative repertoires are closely linked together in discourse methodology. However, there are differences and similarities between them. ${ }^{[24]}$ In this paper the theoretical frame draws from discursive psychology and the concept of interpretative repertoires and negotiations $^{[24-26]}$ and social constructionism. ${ }^{[27]}$ In social constructionism the power of languages can be seen in terms of what they are rather than what they do. The terms used in communication are important in order to communicate our values and beliefs. According to Gergen, ${ }^{[28]}$ constructionism does not try to rule on what is or what is not real. People can use language to construct lived experiences of the world as well as themselves. In social processes in everyday life people negotiate between identities and use social structures of interpretative repertoires, which are always in focus. ${ }^{[24,25]}$ Interpretative repertoires is an analytic term which denotes the extent of culturally available resources that people use when making sense of experiences and construct themselves, events and phenomena when communicating with others.

\subsection{Participants and data collection}

Participants were recruited from three university hospitals and one regional hospital in Norway. The participants were chosen being a family member of a patient who had been critically ill and admitted to the ICU for a minimum of three days within the previous six months.

The cultural background of the sample consisted of three family members, where two were daughters of immigrant fathers who were critically ill and deceased in intensive care units in Norway, as shown in Table 1. One daughter was an immigrant born abroad and the other was Norwegian born with immigrant parents. One had a Chinese (second generation) and one had a Vietnamese cultural origin (first generation). Both daughters were Buddhists and both had an education at university level. One participant (first generation) was the sister of an Eritrean immigrant woman. She was a Christian. Their age ranged from 24 to 29 years and they all spoke Norwegian.

Table 1: Demographics of participant

\begin{tabular}{llllllll}
\hline Participants & Gender/age & $\begin{array}{l}\text { Family relation } \\
\text { to patient }\end{array}$ & $\begin{array}{l}\text { Cultural } \\
\text { background }\end{array}$ & Religion & $\begin{array}{l}\text { Status as } \\
\text { immigrant }\end{array}$ & Education/employment & $\begin{array}{l}\text { Patients' health status } \\
\text { when interviews took } \\
\text { place }\end{array}$ \\
\hline A & +124 & Daughter & Chinese & Buddhist & $\begin{array}{l}\text { Second } \\
\text { generation }\end{array}$ & University/maternity leave & Deceased \\
B & +129 & Daughter & Vietnamese & Buddhist & First generation & $\begin{array}{l}\text { University } \\
\text { college/pre-school teacher }\end{array}$ & $\begin{array}{l}\text { Deceased } \\
\text { C }\end{array}$ \\
\hline+29 & Sister & Eritrean & Christian & First generation & Student/nutritional science & $\begin{array}{l}\text { Not discharged from } \\
\text { ICU }\end{array}$ \\
\hline
\end{tabular}

*ICU $=$ intensive care unit

The data was collected by the first author ( $\mathrm{SH}$ ) conducting narrative interviews. ${ }^{[29]}$ The interviews lasted for approximately one and a half hours. Two participants were interviewed in their homes six to seven weeks after their fathers' death. One of the participants (sister) was interviewed at the hospital when her next of kin was admitted to the hospital. In the interviews, the participants were asked about nursing situations concerning their loved ones, their communication with nurses and their satisfaction and disappointments of being treated as a family member of an acute and critically ill person in an ICU. Examples of the questions asked in the interviews are: "How did you feel about the nurses who were providing care for your father/sister?" "What kind of help did you receive from the nurses?" All the interviews were audio-taped and transcribed verbatim.

\subsection{Data analysis}

The data from the participants was analysed by means of terms from discursive psychology like subject positions, interpretative repertoires and ideological dilemmas as described by Edley ${ }^{[24]}$ and Seymour-Smith and Wetherell. ${ }^{[30]}$ The process of analysis started with the verbatim transcription of the interviews. The transcribed interviews were read several times searching for the participants' selfunderstanding and position as female relatives, and the kind of interpretative repertoires and ideological dilemmas that appeared from the data. The analysing process was created through repetitive readings looking for similarities and differences in the repertoires dominating the material.

\subsection{Ethical considerations}

Ethical approval for the study was obtained from the Regional Committee for Medical Research Ethics in Norway (No.518-04198) which accepted the research protocol and strategies for informed consent. The study was reported to the Norwegian Social Science Data Services, who gave their receipt to fulfil the project (No.11753). All the participants received oral and written information and gave their written 
consent to participate.

\section{Results and discussion}

The participants revealed various comprehensions of their positions as relatives of critically ill family members in an intensive care unit. Their opinions were linked to the participants' gender positions and their cultural background. The discourse analysis resulted in construction of the following themes: being the caring person as a woman, being intertwined between the Western hospital culture and the original family culture, and belonging to a minority in a Western majority culture.

\subsection{Being the caring person as a woman}

Caring for others is often looked upon as basic human nature. The following section analyses the discourse of being a woman and simultaneously being the caring person. The discourse focuses the prerequisite of caring within a family and the female nurses' role in professional care.

A dialogue between the researcher (R:SH) and a participant (P) follows:

R: Do you think it was suitable or not to visit your father being a close family member, being his daughter?

P: I was glad to visit him. He is my father, so I have no objection to support him.

$R:$ Do you think it is good?

P: Yes.

R: Your mother in all this, how did it work for her? She was in a position in-between.

P: She couldn't do anything else, so she had to stay by my father.

R: What do you think about the fact that she was visiting him a lot?

P: He was very glad about that. He didn't want to stay at the hospital alone.

$R$ : When you spent some time there, using your own words, could you say anything about how it was to visit him at the hospital?

$P$ : What do you really mean?

R: Could you stay in his room as much as you wanted or did you have to be there at appointed visiting hours?

P: It was very flexible. I could go whenever I wanted. The nurse said it was OK. At times, there were a lot of visitors and that was somewhat problematic. However, the nurses were very nice, and they explained that there have to be some restrictions in the number of visitors. We did understand that.
The dialogue shows that both the daughter (the participant) and her mother were acting as caring persons for their sick family member.

The dialogue below took place between the Eritrean woman and R:SH.

R: If you'll try to summarize why you are at the hospital, would you say it is because you want to help her with something or is it just because you manage the language?

P: I'm staying here just for my own sake, because I feel uneasy. It's easier and one feels more comfortable when one is near than if one is far away.

$R$ : Is she so seriously ill that her life is threatened?

$P$ : I was really in another country the last four months, from last August. I took my exam. I felt that I was in between. I have just left everything and I came because it was that acute with my sister.

R: Is it uncertain how it will work out with her?

P: Yes, it's quite uncertain. It's quite serious. However, we'll hope for the best.

R: What about her children? You say that your sister is much older than you. How old are they?

P: She has children who are both older and younger than me.

R: Are they also with her a lot?

$P:$ All her children are not here. Two of her children stayed behind in Eritrea.

In the first dialogue the daughter and mother confirm their caring position, while in the second dialogue it is more unclear concerning the sister's considerations in relation to the sick family member. She said that she was visiting her sister for her own sake, not as a representative of the family or as support for her sister. This woman seems to assume a passive position without any specific responsibility for caring for her sick sister. Although she participated in for instance braiding her sister's hair, she was not present in practical nursing situations otherwise. On the other hand she was sitting at her sister's bedside almost all the time, which may be understood as a caring activity. One way to interpret this situation is that the sister was attending her sick sister either because of obligation as a close family member or because her sister was very important for her in her adolescence in Eritrea. These interpretations may be explained as a basic human relationship or more or less due to strong cultural artefacts within the Eritrean family.

The father of one of the daughters had some critical reflections of the intensive care nurses before he died. The daughter expressed herself on behalf of her father:

P: ... at that time he could not visit the bathroom him- 
self. He got a bowl or something in his bed, and it had to be drained manually. He said that the nurses were against doing it for him.

It is strange to think that nurses are against him for this reason because assisting a patient with intimate issues such as giving a bowl in bed is an ordinary caring activity for nurses. One way of interpreting this statement is that the father may feel that his masculinity is endangered when getting help outside the family, because independence and physical strength are main characteristics of masculinity. ${ }^{[10]}$ The reflections were possibly linked to social and cultural constructions of masculinity and being a father of a whole family, because he accused the nurses of being not compliant.

Another interpretation of the caring position as a female member of an immigrant family may be that caring is deeply rooted in women's lives in African and Asian families. When families from these continents migrate to Europe and Northern countries they transfer their "social capital" and habits to their new social setting. ${ }^{[32]}$ According to this comprehension the obvious feminine obligation to take care of family members has probably been integrated in young immigrant daughters when one of their loved ones is admitted to hospital. The caring attitude seems to be rooted in second generation immigrant women's upbringing even if they are born and socialized in a Scandinavian country where this intension is somewhat vague.

\subsection{Being intertwined between the Western hospi- tal culture and the original family culture}

In Norwegian hospitals both the nursing and medical staff are mainly socialized and embedded in the Western culture. Consequently, both health and disease are rooted in Western society with a biomedical view of the body. ${ }^{[31]}$ In the following section there is a discourse between being a relative to a critically ill family member living in the Norwegian culture and the characteristics of belonging to an original non-Western culture.

The participants contrasted their parents' cultural background and their Norwegian friends in a new culture. A dialogue between the daughter of a sick father and the researcher ran like this:

\section{R: Was it more problematic for you than the nurses?}

P: My father shared a room with others and it was somewhat difficult for other patients that we were so many visitors at the same time. However, there was no big group visiting him every day. That took place only few times.

The female participant with a migration history from China described that she automatically acted as carer in an altruistic way: "I was visiting my father often and talked most" and "I am gladly visiting him". Since the daughter spoke Norwegian better than her mother she became the primary contact between the family and the nursing staff: "Initially my mother stayed at the hospital almost all the time." However, "I speak Norwegian better than my uncle, although he speaks very well". In the same sequence the daughter expressed being satisfied with the care of the nurses, mainly women, based on a caring ideology dedicated in their socialization to the caring profession.

The participant above describes herself in a subject position being Norwegian. She identifies herself as a Norwegian citizen. She also positions herself as a modern Norwegian woman with a good education and being a cohabitant with a Norwegian man. In her childhood her mother was at work, and she has a non-Norwegian appearance with her Asian background. When her father became ill she took a caring role by staying at the hospital with her father. This positioning attitude may be linked to constructions of femininity and would presumably be the same for a daughter with Norwegian origin. One interpretation is that this seems quite natural for the daughter and it may also be justified being of Asian origin. In non-Western families the social link between generations may be somewhat stronger compared to traditional Western families. Furthermore, this may be based on a broad and caring family sector where care and cure are mainly offered inside the family, instead of seeking assistance from the professional health systems or the so-called popular sector. ${ }^{[33]}$ In the described situation the participant fulfills the Chinese cultural tradition as a caring daughter showing love and respect for her father. ${ }^{[5]}$ However, being born and raised in a Norwegian society, where the public health care system and caring services are well organized, she negotiated between the Norwegian and the Chinese traditional constructions of femininity. On the other hand it could also be understood as an ideological dilemma when this Chinese family left most of the caring responsibility to the professional nurses, while in the Chinese culture the family is the primary support system and takes on the responsibility for a sick family member also when she/he is in a hospital. ${ }^{[6]}$ One reason for this handover of caring from the daughter's point of view is her fear of disturbing tubes and other medical equipment in connection with her father's intensive care. The father expressed to his daughter some kind of disappointment about the nurses' caring for him, especially linked to personal toilet.

According to language brokering and interpretation in bilingual families, young people have a strong representation of what a "normal" childhood comprises. ${ }^{[34]}$ In immigrant families children and young people often act as language brokers for their parents. ${ }^{[35]}$ Findings in the present study have no clear indications that the daughters of the critically ill immigrant fathers were language brokers. On the other hand, the daughters have grown up in a society where they have learned the Norwegian language, which was different for their fathers. Consequently, the daughters seem to act as indirect language brokers between their fathers who 
were patients in biomedical hospitals and their family members often enclosed by alternative medical adjustments. It is stated that health care professionals need more competence in assessing individual needs among immigrants regarding language barriers and unexpected behaviour related to cultural differences. ${ }^{[36]}$

Another dilemma occurred when the family was visiting her father in the intensive care unit. In the daughter's Chinese family there was an implied attitude that many family members had to visit a family member who is ill, and the ill person could not be left alone when he will pass away. In China, a good death means to stay near one's family and prepare oneself to die without pain and suffering. Buddhists also believe in rebirth and being able to enter death with a positive state of mind. Being surrounded by one's family one can contribute to a rebirth on a higher level of existence. ${ }^{6]}$ The Chinese daughter emphasizes that the nurses met her and the remaining part of her family with flexibility. On the other hand the participant perceived a certain reservation when a nurse said that the family could not visit her father too many at a time. The participant expressed that she understood this precaution, which the nurses justified to protect other patients against noise and stress. According to Chinese customs and the Buddhist religion, the daughter experienced that her father was dressed in his clothes by her relatives after he died. In Norway, private dressing of a dead person is more or less linked to non-religious reasons. ${ }^{\text {[37] }}$

The discourse of being intertwined between the Western hospital culture and the original family culture is expressed in different sections of the interviews. The daughter of the Chinese father said that the family was anxious about doing something wrong due to a lot of equipment connected to the father when he was in ICU. Accordingly the family handed all care to the intensive care nurses. In this way the daughter shows humility and subservience towards professional carers. If this position is linked to her Chinese cultural background it may be contrary to Norwegian and Western self-determination and autonomy, which is distinguished in all Norwegian health legislation. Empowering the patient and taking into account the patients' autonomy has been an increasing issue in the Norwegian health care system in the last decade. Likewise, Western family members and relatives are also anxious when it comes to handle medical equipment which is attached to the patient.

The daughter also enters a subject position of negotiation between the Norwegian and Chinese culture by explaining the difference between her own family and Norwegian ones when she talks about special Chinese ways to talk to each other;

P: If the Chinese talk to each other very loudly it could be looked upon as if they are quarrelling, which can be unpleasant for those listening.

Some cultural differences are expressed in the fact that Chi- nese family members expect to visit and take care of their loved one admitted to hospital in China because they belong to great, collective families. Compared to Scandinavian families there is also a consciousness of the importance of family care, although the small nuclear family is the responsible part. ${ }^{[38]}$ In this condition the daughter also wanted to negotiate in order to minimize the differences by effecting the nurses' explanations to her family members;

P: A huge number from our family came and it was somewhat problematic, but the nurse explained that all of us could not visit our father simultaneously.

In other situations the daughter supports the fact that rules have to be taken into account in order to limit the number of visitors in a specialised unit in hospital. However, the daughter was very satisfied when the nurses arranged a single room for her father at the terminal phase, where all the family members could stay together. In addition, the daughter emphasized the importance of supporting each other when a loved one is dying.

$P:$ In Chinese culture we strive to include the family whenever a person is ill. At the time when someone passes away most of the family have to stay nearby so that the dying person is not left alone.

Although the fulfilment of this need is argued in relation to Chinese cultural tradition, the way of support by staying together could be substantiated by the theory of crises and recent research in coping with grief and sorrow in all families. ${ }^{[39,40]}$

The daughter expressed her offensive positioning towards issues related to the philosophy of life and religion. She quotes: "Religion was a non-theme in hospital," although the whole family are Buddhists. However, the family used Buddhist rituals when the father died; "We dressed him in line with the Buddhist tradition". This is interpreted in the way that the family suppress practicing religion when their loved one is admitted to hospital by adapting the routines so as not to interrupt other patients or families in the Norwegian hospitals. At the same time, the daughter and her family were given a good opportunity by the nurses to fulfill their religious traditions and rituals at the same hospital.

There are similar core qualities to promote a peaceful death across cultures when caring for terminally ill patients in spite of different sociocultural traditions and religions. In Buddhism, the following qualities are important when dying: facilitating the patient's attendance of a peaceful mind, relieve suffering, that family members accept the patient's death and that the patient is not left alone. ${ }^{[41]}$

Differences between cultures became conspicuous regarding analgesics or when questions arise about how to relief pain; "He did not get very much of it (analgesic). He had his ginseng which he took." The patient and his family had confidence in their own culture's methods to relieve pain, 
and the patient got his own alternative drinks or pills in addition to ordinary medication. At the end of his life the father had a lot of pain and then he asked for analgesics: "Do whatever you can, just relieve the pain". In a situation following intense pain the Chinese father sought help in Western medicine, even though he had previously trusted Chinese medicine. This shift may be based on a good experience of Western medicine, or it may be a result of being critically ill, and then it is hard to express his choices and more or less appreciate what Western medicine offers. This is also an example of how to combine complementary and alternative medicine with Western medical tradition. ${ }^{[42]}$

The difference between Norwegian and Chinese hospitals and the family's expectations regarding participation in care was expressed by the daughter in the following way:

$P:$ In China everything is in order, in the way that the family has to help the patient a lot. The nurses do not take care of the patient's daily life at all; even in the intensive care unit the family members do a lot themselves. Here (in Norway) it is quite different. The nurses do everything.

Regarding nursing care in hospitals there is traditionally a power imbalance between the staff and patients, which may be described as an ideological dilemma. Moreover, there has been a shift in the subjectification of the patient from a view that constituted the patient as a set of problematic pathological categories to a way of knowing the patient as more than an object of clinical attention or recognizing the patient as more than a body. ${ }^{[43]}$ The powerlessness of patients in terms of non-compliance could be understood as professional dominance over health care issues. The reconceptualization of the nurse-patient role has transformed the view of the patients into being active participants in their own health care in the last decade. ${ }^{[44]}$ Furthermore, the aspects of power are based upon the social construction of nurses characterizing patient labels as "good" and "bad". ${ }^{[45}$ A situation that often enables powerlessness is when nurses refrain from sharing their knowledge and decision-making powers with patients. ${ }^{[46]}$

A younger sister (participant) of the Eritrean woman grew up together with her in a country in Scandinavia. The sister was seriously ill and admitted to an ICU at the moment of the interview. The Eritrean sister also described the family striving to understand and to receive the most justifiable information possible:

R: Do you and your sisters expect the nursing staff to give correct information or adapted information?

P: I do expect something like this: In our culture we don't say anything directly. Especially regarding death, we don't say: "You are going to die". We rather say: "You are going to be well" and in that way we give hope, because when you later on die, you die. Since I have been here for quite a long time I do want to know what is going to happen with my sister; however I don't tell it all to my aunts and uncles. To them I tell it in other ways. I have told the nurses to tell me the correct things, for instance how things work and so on.

$R$ : In your culture you do not want the truth directly, rather to build hope and expectation. Do you have the impression that the physicians are hesitant, that they are unaware about your culture or other things?

$P$ : No, I don't know. I can't really say how they experienced it, but .... Since we were a great many and they are quite different, we have met a doctor once or twice, and there are no particular ones. If you are concentrated and listen to what they say and what happens, then it works.

$R$ : There are great differences among your family members regarding language, where you live, your educational background, your age and so on ....

P: When I translate I do tell her (sister) something, but I do not tell her everything. I do adapt what I tell her. In our culture it is so that if she wakes up we don't tell her everything that has been said. We will say: "You are well, you're going to improve, you have got your medicine, you will be healthy, don't lose ...," although we do know what will happen. We don't tell the whole truth.

This woman seems to take a paternalistic position when informing the patient about her health condition, and she criticizes the Norwegian nurses who want to tell the biomedical facts directly to the patients. This led to an interpretation that the sister seems to defend the Eritrean culture. She also considers what kind of information she will give the other relatives. It may also be interpreted as she has adopted a Western cultural attitude in the way that she wants to have the correct information about her sibling. In another way it could be understood as the sister relieved the nursing staff by translating and reducing some of the information to the patient (her older sister) in order to strengthen hope. On the other hand, this practice may stress the nurses because they have a mandate to inform patients understandably, in accordingly to the biomedical status and the Norwegian health legislation.

During the women's movement from the 1970s the female and male role have changed to more equal roles concerning the responsibility for home work and work outside the home, particularly in Europe, North America, Oceania ${ }^{[47]}$ and in Norway. ${ }^{[48,49]}$ Furthermore, the nursing profession has been linked to female values ${ }^{[50]}$ and to some extent male stereotypes. ${ }^{[1]}$ Gender discourses regarding the nursing profession are described as constituted by a kind of power which may influence the nurses' actions. ${ }^{[52]}$ According to Foucault ${ }^{[53]}$ power constitutes boundaries in the freedom of the subject and creates different standards of dependence and independence. A person being in a state of less power can feel some kind of powerlessness and suppression. Mi- 
gration may be both burdensome and empowering for young people within a family. Furthermore, the migration process may simultaneously increase their ability to negotiate about what their preferences are and create discriminatory dynamics among family members. ${ }^{[54]}$

\subsection{Belonging to a minority in a Western majority culture}

In sociological terms a minority, often a linguistic minority, is an ethnic group in a society not belonging to the majority. In the following section some actual discourses occurred, like a minority-majority discourse, being a second generation immigrant discourse, and a gender discourse.

The term cultural and symbolic capital ${ }^{[55]}$ is expressed indirectly in an interview with the Vietnamese daughter. In the interview it was obvious that several social dominant discourses arose, which the above-mentioned daughter and interviewer referred to as interpretative repertoires.

The Vietnamese daughter positions herself as a Norwegian inhabitant and legitimates this by saying:

P: I have gone to a Norwegian school, I have Norwegian friends and I feel basically more Norwegian than Vietnamese, to put it that way. Besides, we speak Norwegian at home, in between both Norwegian and Vietnamese. Yes, I have a Norwegian cohabitant. I have my higher education in Norway. I lived two and a half years in another country while I worked there, however I will continue to stay in Norway. After the death of my father we thought about what feelings we had about the hospital stay of my father, about the staff and so on. That left us with very good feelings. But there was not much in relation to the fact that we were from another culture, while our father was in hospital.

These descriptions also point out how she had to defend the position she and her family were put into as Vietnamese by the staff, by the following example: After the death of her father the staff immediately informed other relatives about how to arrange different things, before asking the daughter. The staff may have taken for granted that the family was a large one and that they could turn to anyone in the group. The daughter's position could be characterized as various researchers do as an "In-Between" identity. ${ }^{[56,57]}$

In an opposite position, the Vietnamese woman described herself as an active, competent Norwegian next of kin, who always bothered others and who sought the information needed. Further on, she described herself as a person who had learned a lot about Vietnam and Vietnamese traditions. She also pointed out a kind of a Vietnamese spiritual belief in the expression: "They believe in the transmigration of souls". The interviewer positioned the above-mentioned daughter in a state of choice by using for instance a question like:

R: I would like to ask if you speak like a Norwegian96
Vietnamese or do you speak like a Vietnamese in Norway, because there seems to be a contradiction between your expectations and those of the Vietnamese society in Norway. There seems to be a clash there?

In her answer the participant negotiates between contradictory statements like establishing the identity of oneself or another, or by viewing "two sides of the same coin".

P: In this interview I speak more or less like a Norwegian person. At the same time I see "two sides of the same coin". I speak for myself. However, I got a lot of explanations why different things were done in the way they were done, particularly regarding habits and traditions.

Further on the participant described some of the rituals managed in the family as distinctly divergent, by being either Norwegian or Christian. The interviewer: "I hear you express that Buddhist, religious and ritual wishes were taken into account?" The Vietnamese woman replied:

$P:$ Yes they were, and besides there were not many ritual actions in daily life in hospital, not until the last day of living. The most remarkable thing was that we all stood around my father's bed and I was somewhat surprised when my brother pulled my father's hair after he had died. That may distinguish us from others. And he (the father) had some special clothes on him and a so-called Buddhist garland of roses on his head. That made us somewhat different and others may have thought: "Okay, they are not Norwegian ethnic people and they are not Christian either". This made a difference.

The young Vietnamese daughter was somewhat overwhelmed, and to a certain extent surprised when her brother pulled her dead father's hair. Most of all she was wondering what the nursing staff would think of the Vietnamese otherness compared to the norm among the majority Norwegian population. Firstly, the behaviour was perceived as an overdriven act because the daughter was unaware of Buddhist rituals to help the soul to leave the body when a person has passed away. Secondly, the daughter was unaware of the nurses' knowledge and understanding of the situation, which she presumably was unfamiliar with, and this made her assumption worse. When otherness occurs between a minority and a majority population, as in the case with the Vietnamese Buddhist family and the Norwegian nursing staff, they should take into account the understanding and belief of the other part in order to reveal underlying values, expectations and misunderstandings.

\subsection{Methodological considerations}

To establish rigour in qualitative research, such as collecting and analysing data from individual interviews, the researcher needs to maintain transparency. As an expression of rigour various criteria are intended to maintain trustworthiness in naturalistic paradigm. ${ }^{[58]}$ Morse et al. ${ }^{[59]}$ have argued for a return to validity in qualitative research in or- 
der to obtain rigour through using techniques of verification, by the investigators themselves. In the existing interviews intersubjective validity was maintained to check the participants' answers and responses. In this study a secondary analysis ${ }^{[60,61]}$ of interviews was decided due to the need of exploring deeper understanding of first and second generation immigrants' thoughts and experiences in lifethreatening situations. As discourse analysis is supposed to disclose discourses taken for granted and underlying meanings in communications and relations/interactions between people, this method was chosen. Consequently, the analysis has shown deeper and broader knowledge of first and second generation immigrants and their experiences in encountering critical care nurses.

Due to the limitations of the sample and the relatively low mean age of the participants (mean $=27$ ), the findings in this study would probably have had somewhat more varied positions and dilemmas with a different composition. Even if the sample is small it nevertheless represents different cultural backgrounds, various family relations and unlike status as immigrants (see Table 1). While the sample represents Norwegian immigrants the transferability therefore might be limited to Scandinavian countries. A research group of five researchers participated in the interpretation of the text, where all had obtained a $\mathrm{PhD}$ and all have experiences in studies of gender, nursing, culture and discourse analysis, working in different areas of the clinical and educational discipline of nursing.

\section{Conclusion}

Obvious indicators in this study point out that the women in the immigrant families with a critically ill family member mainly act as the caring person. In spite of this fact there are various dialogues which have been interpreted in the way that female relatives participate in different ways to show their caring intension.

According to the situation of being intertwined between cultures, several ideological dilemmas are revealed regarding different ways of organizing the health system in Nor- way. There are also dilemmas in how much each family entrusts the responsibility for their critically ill loved one to nurses. Furthermore, the anxious attitude among family members regarding medical equipment and nursing procedures on how to take part in caring activities was not associated with the families' cultural background. This anxiety is rather seen as a universal human stress factor when a family is hit by a crisis like serious critical illness. To some extent the present study reveals some interpretative repertoire regarding the lack of encountering the patient as a subject, and regarding powerlessness in the patient role from the family members' point of view.

Different habits and otherness between the Norwegian and non-Norwegian culture regarding death and dying are looked upon as educative both for second generation family members born in Norway and for the nursing staff.

The implications for practice might be that nursing staff has to take into account that immigrant family members in some way want to take part in caring activities with their loved ones and that nurses need to meet family members' wishes by supervision, information and support. Furthermore, the nursing staff should not be afraid to ask families about cultural habits to develop their cultural knowledge when a family member is critically ill and admitted to hospital. It is also important for the nurses to establish a close relation and an open communication between the nursing staff and the patient's spokesperson.

Further research in this area should explore attitudes and understanding of how to manage nursing leadership among patients and their relatives with different cultural backgrounds in Norway and other Scandinavianl countries.

\section{Acknowledgements}

The study has been supported by Hedmark University College, Norway. The authors wish to thank Jeanne Sturmhoefel for reviewing the English language.

\section{Conflicts of Interest Disclosure}

The authors declare that they have no competing interests.

\section{References}

[1] Hjelm K, Albin B, Benato R, et al. Migration and health. Nursing Research and Practice. 2012; 2. http://dx.doi.org/10.1155/2 $012 / 621914$

[2] Eriksen TH. Flerkulturell forståelse [Multicultural comprehension]. Oslo: Universitetsforlaget; 2001. 271p.

[3] Fowers BJ, Richardson FC. Why is multiculturalism good? American Psychologist. 1996; 51(6): 609-621. http://dx.doi.org/1 $0.1037 / 0003-066 X .51 .6 .609$

[4] Høye S, Severinsson E. Professional and cultural conflicts for intensive care nurses. Journal of advanced nursing. 2010; 66(4): 858-867. http://dx.doi.org/10.1111/j.1365-2648.2009.05247.x

[5] Wallin A-M, Ahlström G. From diagnosis to health: a cross-cultural interview study with immigrants from Somalia. Scandinavian Journal of Caring Sciences. 2010; 24: 357-365. http://dx.doi.org $/ 10.1111 / j .1471-6712.2009 .00729 . x$

[6] Wong M-S, Chan SW. The experiences of Chinese family members of terminally ill patients - a qualitative study. Journal of clinical nursing. 2006; (16)12: 2357-2364. http://dx.doi.org/10.11 $11 / \mathrm{j} .1365-2702.2007 .01943 . \mathrm{x}$

[7] SSB Statistics Norwa. Innvandrere og norskfødte med innvandrerforeldre. 1.januar 2013. Available from: http://www.ssb.no/b efolkning/statistikker/innvbef 
[8] Leseth A, Solbrække KN. Profesjon, Kjønn og etnisitet. Tidsskrift for Kjønnsforskning. 2011; (1): 77-81.

[9] West C, Zimmerman DH. Doing gender. In: Fenstermaker S, West C, editors. Doing gender, doing difference: inequality, power, and institutional change. New York: Routledge; 2002: 3-25. 244p.

[10] Connell RW. Masculinities. Cambridge: Polity Press; 2005. 324p.

[11] Rosaldo MZ. Women, culture and society: a theoretical overview. In: Rosaldo MZ, Lamphere L, editors. Woman, culture and society. Stanford University Press; 1974: 17-43. 360p.

[12] Lewellen TC. Political anthropology. London: Praeger Publishers; 2003. 262p.

[13] Morse J, Solberg S, W Neander, et al. Concepts of caring and caring as a concept. Advances in Nursing Science. 1990; (13)1: 1-14. http://dx.doi.org/10.1097/00012272-199009000-00002

[14] Thomas E, Sexton JB, Helmreich RL. Discrepant attitudes about teamwork among critical care nursesand physicians. Critical Care Medicine. 2003; (31)3: 956-959. http://dx.doi.org/10.1097 /01. CCM. 0000056183.89175 .76

[15] Kirkham S. Nurses' descriptions of caring for culturally diverse clients. Clinical nursing research. 1998; 7(2): 125-146. http:// dx.doi.org/10.1177/105477389800700204

[16] Nailon RE. Nurses' concerns and practices with using interpreters in the care of Latino patients in theemergency department. Journal of transcultural nursing. 2006; 17(2): 119-128. http://dx.doi.o $\mathrm{rg} / 10.1177 / 1043659605285414$

[17] Cioffi J. Communicating with culturally and linguistically diverse patients in an acute care setting:nurses' experiences. International journal of nursing studies. 2003; 40(3): 299-306. http://dx.doi . org/10.1016/S0020-7489(02)00089-5

[18] Høye S, Severinsson E. Intensive care nurses' encounters with multicultural families in Norway: An exploratory study. Intensive and critical care nursing. 2008; 24(6): 338-348. http://dx.doi.org $/ 10.1016 / \mathrm{j}$. iccn.2008.03.007

[19] Ellingsen D. Statistics of importance. Immigration and Immigrants. 2010. Available from: http://www.ssb.no/english/subject s/02/sa_innvand_en/sa122/importance.pdf

[20] Wright LM, Leahey M. Nurses and families. A guide to family assessment and intervention. Philadelphia: F.A. Davis Comp.; 2000. $384 \mathrm{p}$.

[21] White R. Discourse analysis and social constructionism. Nurse researcher. 2004; 12(2): 7-16. http://dx.doi.org/10.7748/nr2 $004 \cdot 10 \cdot 12 \cdot 2 \cdot 7 \cdot c 5935$

[22] Traynor M. Discourse analysis. Nurse researcher. 2004; 12(2): 4-6. http://dx.doi.org/10.7748/nr2004.10.12.2.4.c5934

[23] Thome S. Ethical and representational issues in qualitative secondary analysis. Qual Health Research. 1998; 8(4): 547-555. http: //dx.doi.org/10.1177/104973239800800408

[24] Edley N. Analysing masculinity: interpretative repertoires, ideological dilemmas and subjective positions. In: Wetherell M, Taylor S, Yates SJ, editors. Discourse as data: a guide for analysis. London: Sage Publications; 2001: 189-228. 338p.

[25] Taylor S. Locating and conducting discourse analytic research. In: Wetherell M, Taylor S, Yates SJ, editors. Discourse as data: a guide for analysis. London: Sage Publications; 2001: 5-48. 338p.

[26] Wetherell M, Taylor S, Yates S. Discourse as data: a guide to analysis. London: Sage Publications; 2001.

[27] Burr V. Social constructionism. Psychology Press; 2003. 229p.

[28] Gergen KJ. Social construction in context. London: Sage Publications; 2009. 240p.

[29] Bates JA. Use of narrative interviewing in everyday information behaviour research. Library \& Information Science Research. 2004; 24(1): $15-28$

[30] Seymour-Smith S, Wetherell M. "What he hasn't told you ...": investigating the micro-politics of gendered support in heterosexual couples' co-constructed accounts of illness. Feminism \& psychology. 2006; 16(1): 105-127. http://dx.doi.org/10.1177/095 9-353506060826

[31] Hahn RA, Gaines AD. Physicians of Western Medicine: Anthropological Approaches to Theory and Practice. Springer Science \& Business Media; 1985. 345p
[32] Isaksen LW, Devi SU, Hochschild AR. Global care crisis: A problem of capital, care chain, or commons? American Behavioral Scientist. 2008; 52(3): 405-425. http://dx.doi .org/10.1177/000 2764208323513

[33] Kleinman A. Patients and healers in the context of culture. University of California Press; 1980. 427p.

[34] Crafter S, O'Dell L, De Abreu G, et al. Young peoples' representations of 'atypical' work in English society. Children \& Society. 2009; 23(3): 176-188. http://dx.doi.org/10.1111/j.109 9-0860.2008.00165.x

[35] Cline T, Crafter S, O’Dell L, et al. Young people's representations of language brokering. Journal of Multilingual and Multicultural development. 2011; 32(3): 207-220. http://dx.doi.org/10.1080 /01434632.2011.558901

[36] Hultsjö S, Hjelm K. Immigrants in emergency care: Swedish health care staff's experiences.International Nursing Review. 2005; 52(4): 276-285. http://dx.doi.org/10.1111/j.1466-7657. 2005.00418. $\mathrm{x}$

[37] Berthelsen E. Farvel: en fortolkning av et pleiepersonales erfaringer med å pleie døende og stelle døde. [dissertation]. [Troms $\varnothing$ ]: University of Troms $\varnothing ; 2010.202 p$.

[38] Sandberg J, Eriksson H, Holmgren J, et al. Keeping the family balance: adult daughters' experiences of role and strategies when supporting caring fathers. European journal of social work. 2009; 12(2): 233-245. http://dx.doi.org/10.1080/13691450802567499

[39] Wijngaards-de Meij L, Stroebe M, Stroebe W, et al. The impact of circumstances surrounding the death of a child on parents' grief. Death studies. 2008; 32(3): 237-252. http://dx.doi.org/10. 1080/07481180701881263

[40] Stroebe M, Schut H. The dual process model of coping with bereavement: a decade on. Journal of death and dying. 2010; 61(4): 273-289. http://dx.doi.org/10.2190/OM.61.4.b

[41] Kongsuwan W, Keller K, Touhy T, et al. Thai Buddhist intensive care unit nurses' perspective of a peaceful death: an empirical study. International journal of palliative nursing. 2010; 16(5): 241-247. http://dx.doi.org/10.1111/j.1478-5153.2012.00495.x

[42] Suzuki N. Complementary and alternative medicine: a Japanese perspective. Evidence based complementary and alternative medicine. 2004; 1(2): 113-118. http://dx.doi.org/10.1093/ecam/ne h029

[43] Ma C. Nursing work, nurses' knowledge, and the subjectification of the patient. Sociology of health illness. 1992; 14(4): 472-487. http://dx.doi.org/10.1111/1467-9566.ep10493107

[44] Playle JF, Keeley P. Non-compliance and professional power. Journal of advanced nursing. 1998; 27(2): 304-311. http://dx. doi.o $\mathrm{rg} / 10.1046 / \mathrm{j} .1365-2648.1998 .00530 . \mathrm{x}$

[45] Johnson M. Nursing power and social judgement. An interpretive ethnography of a hospital ward. University of Central Lancashire; 1997. $218 \mathrm{p}$

[46] Henderson S. Power imbalance between nurses and patients: a potential inhibitor of partnership in care. Journal of clinical nursing. $2003 ; 12(4)$ : 501-508. http://dx.doi.org/10.1046/j.1 365-2702.2003.00757.x

[47] Buvinic M. Promoting gender equality. International Social Science Journal. 1999; 51(162): 567-574. http://dx.doi.org/10.1111 /1468-2451.00228

[48] Kvigne K, Kirkevold M. A feminist perspective on stroke rehabilitation: the relevance of de Beauvoir's theory. Nursing philosophy. 2002; 3(2): 79-89. http://dx.doi.org/10.1046/j.1466-769 $\mathrm{X} .2002 .00088 . \mathrm{x}$

[49] Holter ØG, Svare H, Egeland C. Gender equality and quality of life. A Norwegian perspective. Nordic Gender Institute; 2009. 272p.

[50] Jinks AM, Bradley E. Angel, handmaiden, battleaxe or whore? A study which examines changes in newly recruited student nurses' attitudes to gender and nursing stereotypes. Nurse education today. 2004; 24(2): 121-127. http://dx.doi.org/10.1016/j.nedt. 2003.10.011

[51] Eriksson H. Den diplomatiska punkten: maskulinitet som kroppsligt identitetsskapande projekt i svensksjuksköterskeutbildning [The 
Diplomatic Point - Masculinity as an Embodied Identity Project inSwedish Nursing Education] [dissertation]. [Gothenburg]: University of Gothenburg; 2002. 157p.

[52] Ceci C. Nursing, knowledge and power: A case analysis. Social science and medicine. 2004; 59(9): 1879-1889. http://dx.doi.org /10.1016/j.socscimed. 2004.02.022

[53] Foucault M. Diskursens ordning [The order of the discourse]. Brutus Östlings Bokförlag Symposion; 1993.

[54] Pantea M-C. Young people's perspectives on changing families' dynamics of power in the context of parental migration. Young. 2011; 19(4): 375-395. http://dx.doi.org/10.1177/1103308 81101900402

[55] Bourdieu P. Language and symbolic power. Harvard University Press; 1991. 302p. PMID:10044317.

[56] Sargent CF. Reproductive strategies and Islamic discourse: Malian migrants negotiate everyday life in Paris, France. Medical anthropology quarterly. 2006; 20(1): 31-49. http://dx.doi.org/10. $1525 / \mathrm{maq} .2006 \cdot 20 \cdot 1 \cdot 31$
[57] Kristiansen M, Tjørnhøj-Thomson T, Krasnik A. Sometimes you just have to walk alone - meanings of emotional support among Danish-born and migrant cancer patients. Journal of psychosocial oncology. 2010; 28(6): 699-717. http://dx.doi.org/10.1080 /07347332.2010.516808

[58] Lincoln YS, Guba EG. Naturalistic Inquiry. SAGE Publications; 1985. 416p.

[59] Morse JM, Barrett M, Mayan M, et al. Verification strategies for establishing reliability and validity in qualitative research. International journal of qualitative methods. 2002; 1(2): 1-19.

[60] Seng JS, Low LK, Sparbel KJH, et al. Abuse-related post-traumatic stress during the childbearingyear. Journal of Advanced Nursing. 2004; 46(6): 604-613. http://dx.doi.org/10.1111/j.1 365-2648.2004.03051.x

[61] Mantzoukas S, Jasper M. Types of nursing knowledge used to guide care of hospitalized patients.Journal of Advanced Nursing. 2008; 62(3): 318-326. http://dx.doi.org/10.1111/j.1365-2648. $2007.04587 . x$ 